\title{
Impact Behavior of Recycled Aggregate Concrete Based on Split Hopkinson Pressure Bar Tests
}

\author{
Yubin Lu, ${ }^{1}$ Xing Chen, ${ }^{2}$ Xiao Teng, ${ }^{2}$ and Shu Zhang ${ }^{2}$ \\ ${ }^{1}$ Key Laboratory of Testing Technology for Manufacturing Process (Ministry of Education), \\ Southwest University of Science and Technology, Mianyang 621010, China \\ ${ }^{2}$ School of Manufacturing Science and Technology, Southwest University of Science and Technology, Mianyang 621010, China \\ Correspondence should be addressed to Yubin Lu; yubinluzju@hotmail.com
}

Received 7 November 2012; Revised 12 February 2013; Accepted 12 February 2013

Academic Editor: Alex Li

Copyright (C) 2013 Yubin Lu et al. This is an open access article distributed under the Creative Commons Attribution License, which permits unrestricted use, distribution, and reproduction in any medium, provided the original work is properly cited.

\begin{abstract}
This paper presents the experimental results of recycled aggregate concrete (RAC) specimens prepared with five different amounts of recycled coarse aggregate (RCA) (i.e., 0, 25\%, 50\%, 75\%, and 100\%) subjected to impact loading based on split Hopkinson pressure bar tests. Strain-rate effects on dynamic compressive strength and critical strain of RAC were studied. Results show that the impact properties of RAC exhibit strong strain-rate dependency and increase approximately linearly with strain-rate. The transition point from low strain-rate sensitivity to high sensitivity decreases with the increase of matrix strength.
\end{abstract}

\section{Introduction}

The amount of construction and demolition waste (C\&DW) has increased enormously over the last decade in the entire world. The recycling of waste concrete is beneficial and necessary for the environmental preservation and effective utilization of natural resources. The use of recycled coarse aggregate (RCA) obtained from C\&DW in new concrete is a solution for the effective utilization of construction and demolition waste.

In practice, there are many incidents in which the structures undergo impact or explosion loading. The behavior of concrete structures subjected to dynamic loading is different from that under quasistatic loading. Due to the short duration of loading, the strain-rate of material is significantly higher than that under quasistatic loading conditions. Therefore, the present paper focuses on the behavior of recycled aggregate concrete (RAC) specimens prepared with different amounts of RCA under dynamic loading based on split Hopkinson pressure bar (SHPB) tests.

Many researchers have studied the dynamic behavior of plain, composite, and reinforced concrete specimens with natural coarse aggregates (NCA) based on SHPB tests. For example, $\mathrm{Li}$ and $\mathrm{Xu}$ [1] studied the impact mechanical properties of basalt fiber reinforced geopolymeric concrete based on a SHPB system; Rong et al. [2] investigated the dynamic compression behavior of ultrahigh performance cement based composites; Wang et al. [3] obtained the stress-strain relationship of steel fiber-reinforced concrete under dynamic compression based on SHPB. For RAC, Chakradhara Rao et al. [4] have studied its behavior under low velocity drop weight impact load. But no attempts have been made on the behavior of RAC specimens based on SHPB tests. Comparing with the drop weight impact technique, the SHPB technique has many advantages, like attaining higher striking velocities and thus higher strain-rates and can obtain stress-strain curves.

In this paper, the impact compression experiment is described in detail, including the preparation of RAC specimens and the SHPB test, in Section 2. Results of stress versus strain curves, failure patterns, strength, deformation, and energy absorption are presented and discussed in Section 3, followed by conclusions in Section 4 .

\section{Experiments}

2.1. Materials. Raw materials used for RAC specimens are (1) RCA taken from waste concrete of a Mianyang road, the design strength of this waste concrete is unclear, and the waste concrete is broken by a jaw crusher, graded and cleaned to 
TABLE 1: The mix proportions of RAC test specimens.

\begin{tabular}{lcccccc}
\hline Mix designation & Cement & Water & Sand & NCA & RCA & Replacement ratio/\% \\
\hline PC-0 & 1 & 0.477 & 1.465 & 3.418 & 0 & 0 \\
RC-25 & 1 & 0.477 & 1.465 & 2.564 & 0.854 & 25 \\
RC-50 & 1 & 0.477 & 1.465 & 1.709 & 1.709 & 50 \\
RC-75 & 1 & 0.477 & 1.465 & 0.854 & 2.564 & 75 \\
RC-100 & 1 & 0.477 & 1.465 & 0 & 3.418 & 100 \\
\hline
\end{tabular}

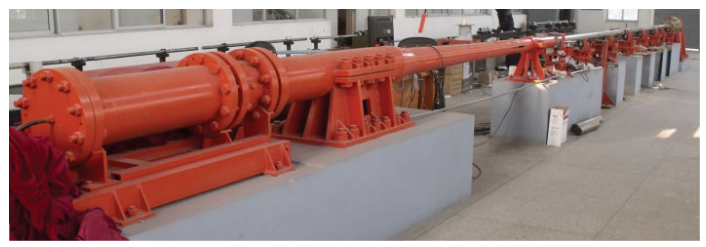

(a) Overall setup

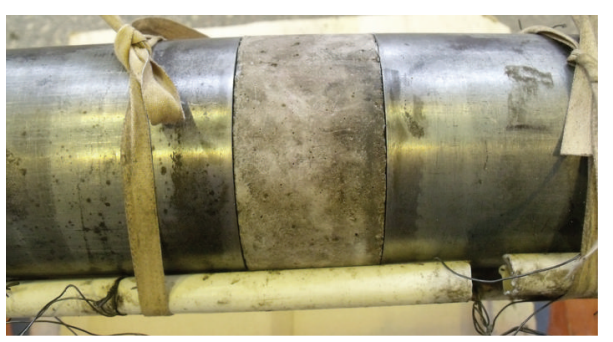

Before impact

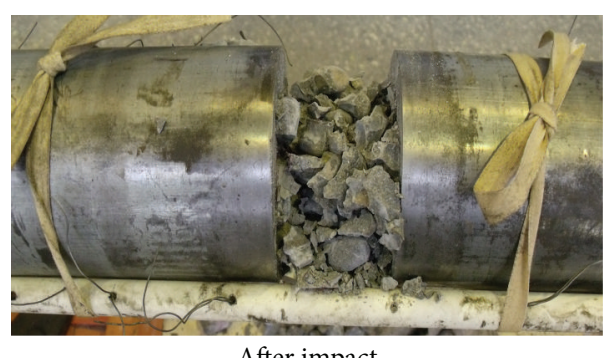

After impact

(b) Specimen, incident, and transmitted bars

FIGURE 1: The 100-mm-diameter SHPB apparatus.

RCA of diameters from 10 to $20 \mathrm{~mm}$; (2) NCAs are natural cobbles of diameters from 10 to $20 \mathrm{~mm}$; (3) ordinary Portland cement of 42.5 grade is used; (4) fine aggregates are natural river sand of continuous grading with fineness modulus of 2.28; and (5) Mianyang tap water is used.

Concrete mix proportions largely influence the mechanical properties of concrete. To ensure the flowability during concreting and the strength after molding of RAC, the mix proportions of RAC specimens used in this study are cement: water : fine aggregate: coarse aggregate $=$ $1: 0.477: 1.465: 3.418$, where coarse aggregates include NCA and RCA. According to the difference of replacement ratios of RCA, there are five different types of specimens, as shown in Table 1. PC-0 stands ordinary concrete specimens, and RC-25, RC-50, RC-75, and RC-100 stand RAC specimens with RCA replacement ratios of $25 \%, 50 \%, 75 \%$, and $100 \%$, respectively.

2.2. SHPB Tests. Dynamic compression tests of RAC are performed on $100 \mathrm{~mm}$ diameter SHPB setup with $\phi 100 \times$ $50 \mathrm{~mm}$ cylinder specimens. The SHPB setup is shown in Figure 1. The length of the projectile, incident and transmission bar is $0.5,4.5$, and $2.5 \mathrm{~m}$, respectively. The distance from the strain gauges on the incident bar and transmission bar and the interface of incident bar/specimen or specimen/transmission bar is $2.5 \mathrm{~m}$ and $0.5 \mathrm{~m}$. The projectile, incident, and transmission bar are made of $48 \mathrm{CrMoA}$ and have Young's modulus of $210 \mathrm{GPa}$, density of $7850 \mathrm{~kg} / \mathrm{m}^{3}$,
Poisson's ratio of $0.25-0.3$, theoretical elastic wave velocity of $5172 \mathrm{~m} / \mathrm{s}$, and measured elastic wave velocity of $5200 \mathrm{~m} / \mathrm{s}$. The projectile bar is accelerated by the use of air pressure, and the projectile striking velocity is measured by laser velocimeter with the light distance of $0.1 \mathrm{~m}$.

To ensure that the SHPB test results are valid, a critical condition that shall be satisfied is the stress equilibrium along the loading axial. Ravichandran and Subhash [5] proved that some time is needed for the specimen to achieve stress equilibrium state in the loading direction after it is first loaded, and this time is approximately $4 \tau_{s}$ (where $\tau_{s}$ is the transit time for the leading edge of the stress pulse traveling through the specimen). Pulse shaping technique [6] can prolong the rise time of incident pulse, so that specimens have enough time to obtain stress equilibrium. Besides, it can smooth waveforms and eliminate waveform oscillations. In this study, for striking velocities $<6 \mathrm{~m} / \mathrm{s}, 6-10 \mathrm{~m} / \mathrm{s}$ and $10-$ $12 \mathrm{~m} / \mathrm{s}$, three different kinds of pulse shapers are used, that is, pasteboard of $0.67 \mathrm{~mm}$ thickness and $54.27 \mathrm{~mm}$ diameter, H62 brass of $1 \mathrm{~mm}$ thickness and $20 \mathrm{~mm}$ diameter, and H62 brass of $1 \mathrm{~mm}$ thickness and $30 \mathrm{~mm}$ diameter pulse shapers were, respectively, designed to improve incident waveforms. The quasistatic tensile stress-strain curves of standard H62 brass specimens are tested on a servohydraulic machine equipped with two cameras. Software based on a procedure called digital image correlation (DIC) was applied to process the images and subsequently determine the strains. Before 


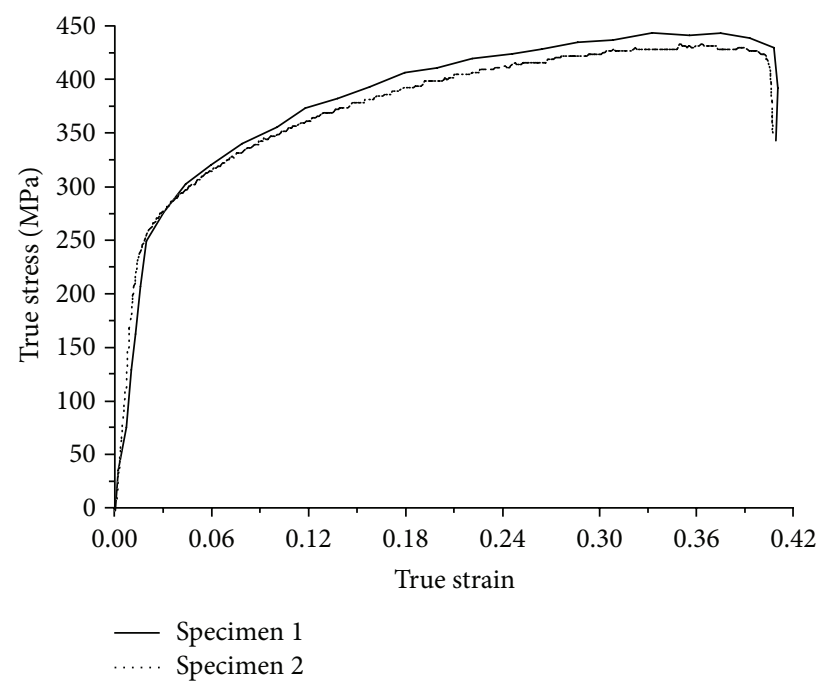

FIgURE 2: Quasi-static tensile stress-strain curves of H62 brass.

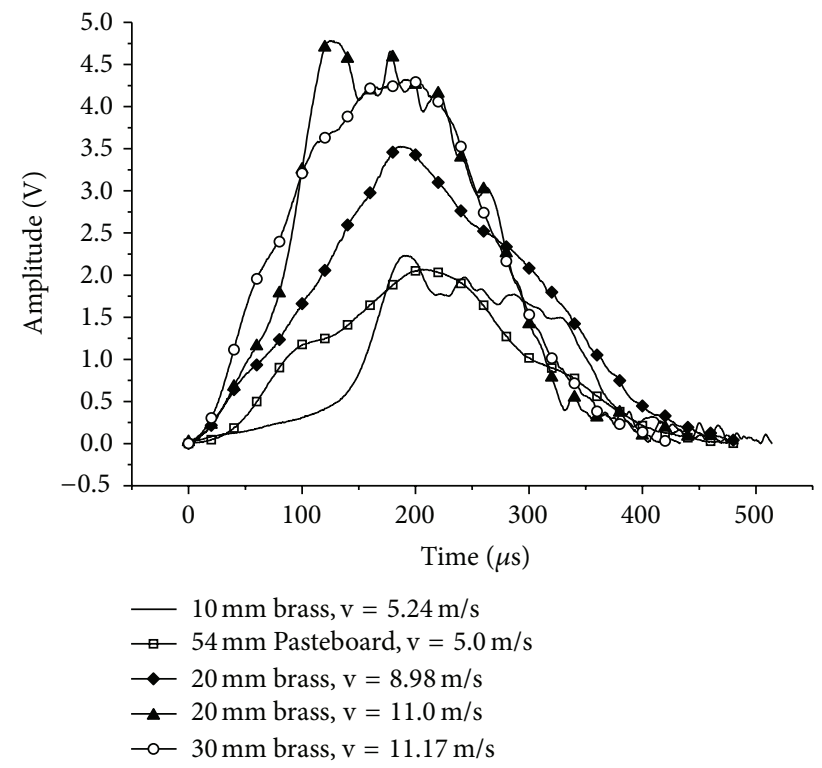

FIGURE 3: Incident waveforms shaped with different pulse shapers.

each test, a random pattern with good contrast was applied to the surface of the specimen. This pattern deforms with the sample. The tensile stress-strain curves are shown in Figure 2. The Young's modulus is $100 \mathrm{GPa}$.

Figure 3 presents the comparison of shaped incident pulses by different pulse shapers. After using pulse shapers, the total duration of incident pulse is $433.5-514.5 \mu$ s and the rise time is up to 124.5-204.0 $\mu$ s. Except the use of brass pulse shaper with $20 \mathrm{~mm}$ in diameter when the striking velocity is $11.0 \mathrm{~m} / \mathrm{s}$ (the rise time is $124.5 \mu \mathrm{s}$ ), other pulse shapers provide sufficient time for the specimen to achieve stress equilibrium state in the loading direction. However, for low striking velocity (about $5 \mathrm{~m} / \mathrm{s}$ ), the shaped effect of pasteboard is better than that of brass with $10 \mathrm{~mm}$ in diameter. Figure 4 shows the typical incident, reflected and transmitted

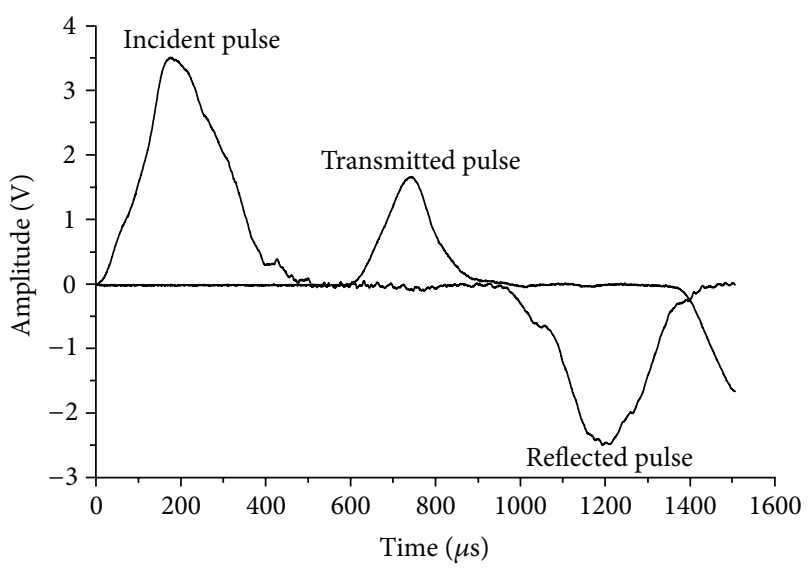

FIGURE 4: Incident, reflected, and transmitted waveforms shaped with a brass pulse shaper $(\phi 20 \times 1 \mathrm{~mm})$ for a NAC specimen under the striking velocity of $8.95 \mathrm{~m} / \mathrm{s}$.

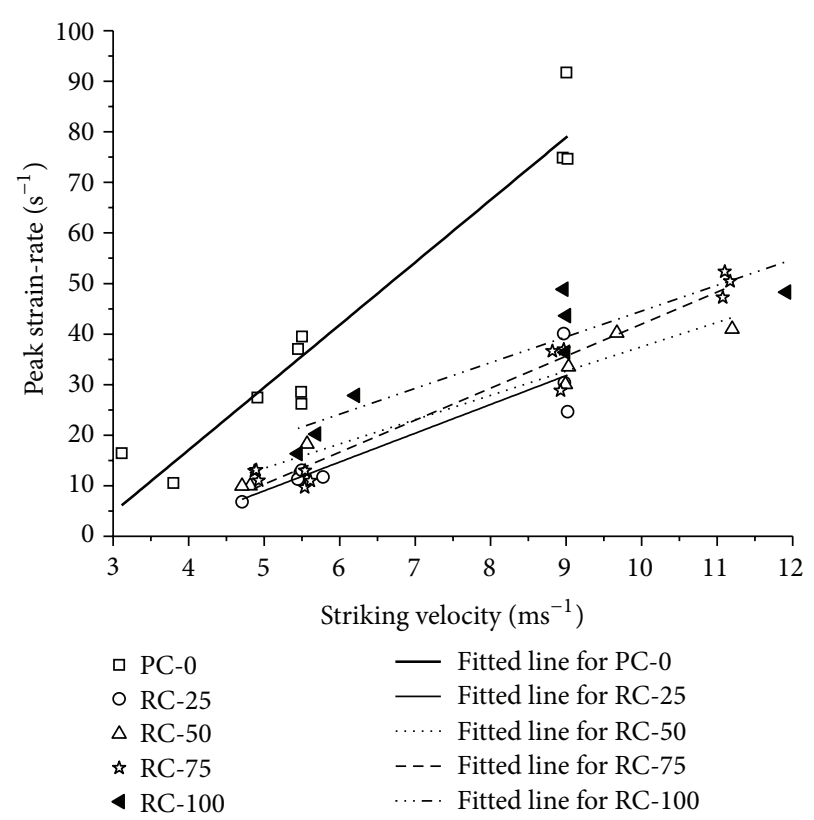

FIgure 5: Peak strain-rate versus striking velocity with fitted lines.

waveforms of a natural aggregate concrete (NAC) specimen shaped by a brass pulse with diameter of $20 \mathrm{~mm}$. It shows that the dispersion of strain pulse during SHPB test is eliminated by the use of this pulse shaper.

In the study, various strain-rates were obtained by means of changing the projectile striking velocity. As shown in Figure 5, the relationship between the peak strain-rate $\dot{\varepsilon}_{s}$ (the strain-rate corresponding to the peak strength) and impact velocity $v(\mathrm{~m} / \mathrm{s})$ can be approximately linearly expressed as

$$
\dot{\varepsilon}_{s}=A+B v,
$$

where parameters $A$ and $B$, together with the coefficients of determination $R^{2}$, for RAC specimens are summarized in Table 2. It is observed from Figure 5 that at the same striking velocity, the NAC specimens (PC-0) can attain higher peak 
TABLE 2: Parameters in (1) for RAC specimens.

\begin{tabular}{lccccc}
\hline & PC-0 & RC-25 & RC-50 & RC-75 & RC-100 \\
\hline$A$ & -32.41 & -19.50 & -10.59 & -21.46 & -6.51 \\
$B$ & 12.37 & 5.70 & 4.81 & 6.35 & 5.10 \\
$R^{2}$ & 0.92 & 0.84 & 0.95 & 0.96 & 0.78 \\
\hline
\end{tabular}

strain-rate than RAC specimens (RC-25, RC-50, RC-75, and RC-100).

\section{Experimental Results and Discussion}

3.1. Stress versus Strain Curves and Failure Patterns. SHPB experiments were conducted at various strain-rates in the range of $10-100 \mathrm{~s}^{-1}$. Average engineering stress $\sigma(t)$ on the two faces of the SHPB specimen and average engineering strain-rate $\dot{\varepsilon}(t)$ and strain $\varepsilon(t)$ over the length of the specimen are calculated from incident strain $\varepsilon_{i}(t)$, reflected strain $\varepsilon_{r}(t)$, and transmitted strain $\varepsilon_{t}(t)$ signals in the bars with threewave method, that is,

$$
\begin{gathered}
\sigma(t)=\frac{A_{b}}{2 A_{s}} E_{b}\left[\varepsilon_{i}(t)+\varepsilon_{r}(t)+\varepsilon_{t}(t)\right] \\
\dot{\varepsilon}(t)=\frac{c_{b}}{L_{s}}\left[\varepsilon_{i}(t)-\varepsilon_{r}(t)-\varepsilon_{t}(t)\right] \\
\varepsilon(t)=\frac{c_{b}}{L_{s}} \int_{0}^{t}\left[\varepsilon_{i}(t)-\varepsilon_{r}(t)-\varepsilon_{t}(t)\right] d t
\end{gathered}
$$

where $A_{b}, E_{b}$, and $c_{b}$ are the original cross-sectional area, Young's modulus, and elastic wave speed of the bars, respectively, and $A_{s}$ and $L_{s}$ are the original cross-sectional area and original length of the specimen, respectively. Stress versus strain curves obtained from SHPB tests are shown in Figure 6. The stress increases almost linearly initially and then decreases after the stress achieves the peak value. The strain-rate effect on the peak stress can be seen clearly.

Figure 7 presents the failure patterns of RAC specimens after impact under various striking velocities. However, to save the space, only typical photos are presented and others are omitted. It is observed that the failure pattern of RAC specimens is similar to that of NAC specimens. The impact failure becomes more and more violent and decisive with the increase of striking velocity. Under low striking velocity (i.e., $<4 \mathrm{~m} / \mathrm{s}$ ), the RAC specimens are failed by the appearance of visible cracks. When the striking velocity is in the range of 4 and $6 \mathrm{~m} / \mathrm{s}$, the RAC specimens are failed by the disintegration of the tested cylinders mainly into big pieces. While the striking velocity is further increased, the RAC specimens fractured mainly in very fine fragments. For the striking velocity is over $11 \mathrm{~m} / \mathrm{s}$, many fine fragments are flown away such that only part failed specimens are recycled.

3.2. Strength. Figure 8(a) shows the dynamic compressive strength $f_{\text {cd }}$ versus peak strain-rate for RAC specimens, which indicate that the impact properties of RAC are apparently strain-rate dependent and increase approximately linearly with the increase of peak strain-rate.
TABle 3: Parameters in (3) for RAC specimens.

\begin{tabular}{lccccc}
\hline & PC-0 & RC-25 & RC-50 & RC-75 & RC-100 \\
\hline$C$ & 1.28 & 1.19 & 1.08 & 1.04 & 1.03 \\
$D$ & 0.054 & 0.037 & 0.014 & 0.0074 & 0.0071 \\
$E$ & 0.23 & 0.65 & 0.37 & 0.73 & -0.25 \\
$F$ & 1.31 & 0.57 & 0.26 & 0.40 & 1.00 \\
$\dot{\varepsilon}_{c}$ & 6.65 & 10.40 & 11.75 & 6.65 & 19.95 \\
$R^{2}$ & 0.64 & 0.74 & 0.57 & 0.29 & 0.82 \\
\hline
\end{tabular}

It is believed that the dynamic increase factor (DIF) of concrete, which is the ratio of dynamic compressive strength to its corresponding quasi-static value, is directly dependent on the logarithm of the strain-rate. Therefore, the strain-rate dependence of DIF of RAC at strain-rates in the range of 10$100 \mathrm{~s}^{-1}$ can be defined as

$$
\mathrm{DIF}= \begin{cases}C+D \lg \left(\dot{\varepsilon}_{s}\right) & 10^{-5} \leq \dot{\varepsilon}_{s} \leq \dot{\varepsilon}_{c} \mathrm{~s}^{-1}, \\ E+F \lg \left(\dot{\varepsilon}_{s}\right) & \dot{\varepsilon}_{c} \leq \dot{\varepsilon}_{s} \leq 100 \mathrm{~s}^{-1},\end{cases}
$$

where the parameter values of $C, D, E$, and $F$, together with the transition strain-rate $\dot{\varepsilon}_{c}$ from a low strain-rate sensitivity to a high sensitivity and the coefficients of determination $R^{2}$, are summarized in Table 3.

Equation (3), illustrated in Figure 9, clearly indicates that there is a sharp increase in DIF beyond the transition strainrate of $\dot{\varepsilon}_{c}$ for RAC specimens. From Figure 9, it is found that DIF is reduced with the increase of RCA replacement ratio. When the strain-rates are over the transition strain-rate, the DIF of RAC specimens is largely smaller than that of NAC specimens.

3.3. Deformation. Critical compressive strain $\varepsilon_{c}$, which is defined as the stain when the stress reaches the peak, was used to describe the deformation property of RAC specimens. Bischoff and Perry [7] summarized a wide range of concretes of various quasi-static strengths and strain-rates, showing that significant increases in critical compressive strain were sometimes observed during impact loading, although these increases were generally less than those observed for strength. Figure 8(b) depicts a tendency that the critical compressive strain increases with the peak strain-rate, and the critical compressive strain of RAC specimens is smaller than that of NAC specimens. The relationship between critical compressive strain and peak strain-rate can be expressed as

$$
\varepsilon_{c}=a+b \dot{\varepsilon}_{s}
$$

in which the parameter values of $a$ and $b$, and the coefficients of determination $R^{2}$, are summarized in Table 4 .

3.4. Energy Absorption. Specific energy absorption $U$, which is expressed as the energy absorbed per unit volume of material [8], is used to describe the energy absorption property of RAC specimens and equals the area below the stress-strain curves. As shown in Figures 8(c)-8(d), specific energy absorption is $51.17-911.74 \mathrm{~kJ} / \mathrm{m}^{3}$ at peak strain-rate in the range of $10-100 \mathrm{~s}^{-1}$ and increases with the increase of 

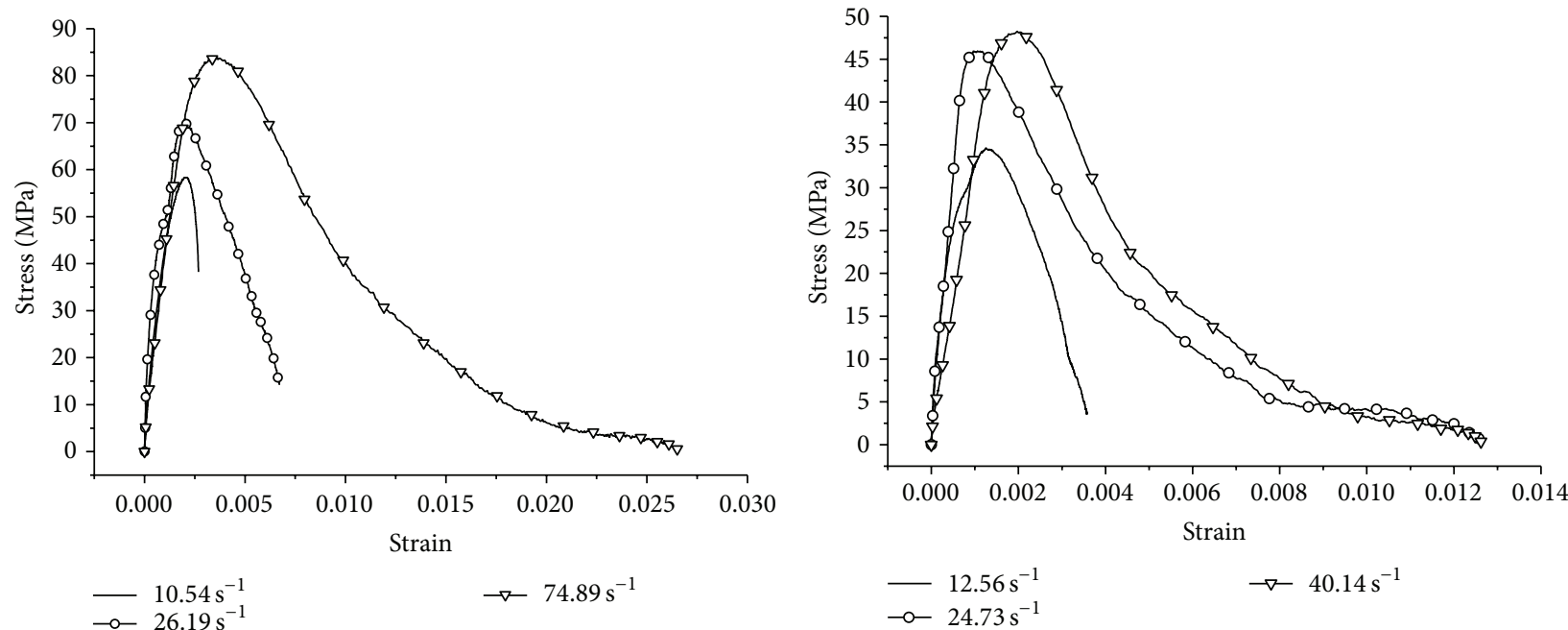

(a)

(b)
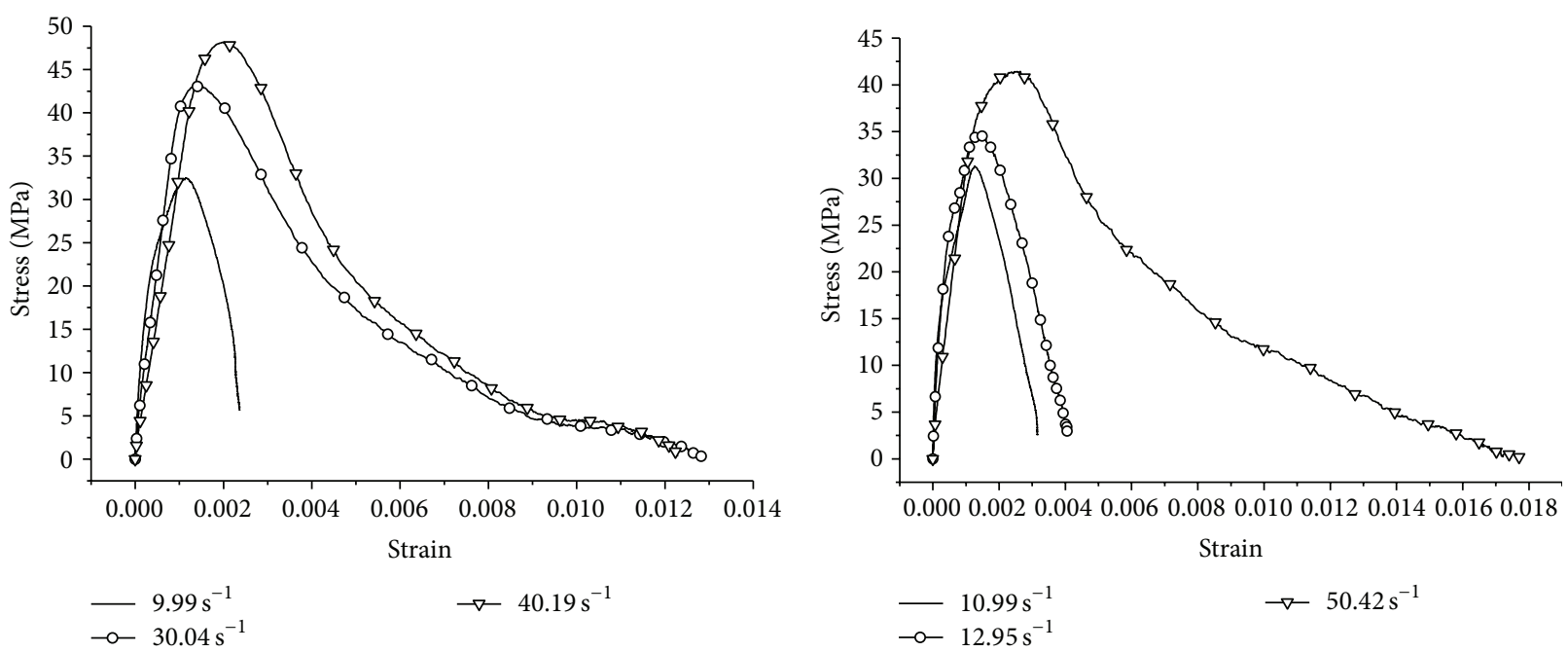

(c)

(d)

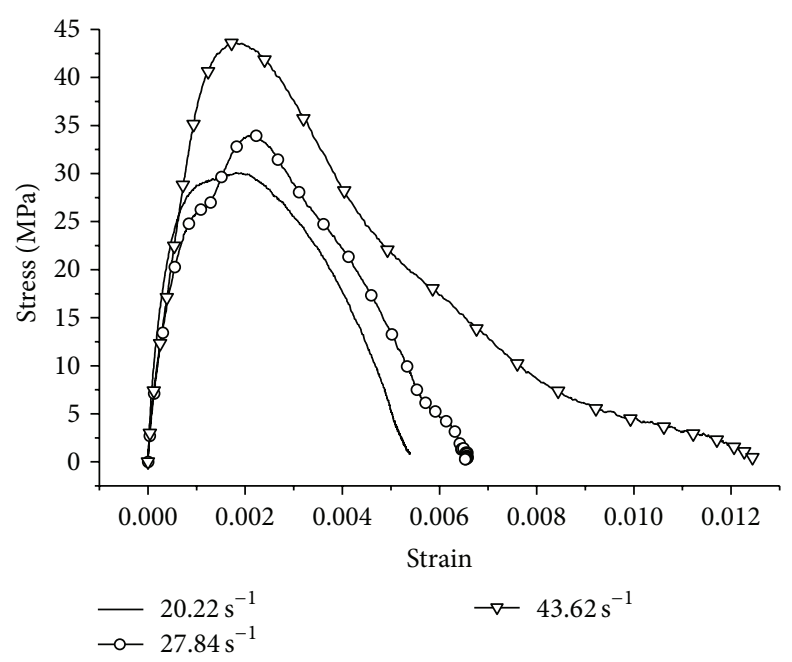

(e)

FIGURE 6: Stress versus strain curves of RAC specimens. 


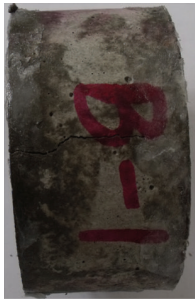

$3.1 \mathrm{~m} / \mathrm{s}$

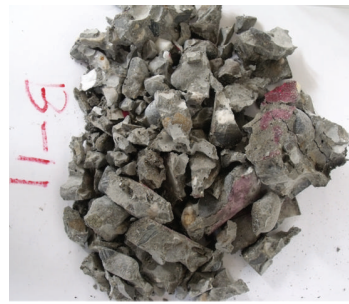

$4.9 \mathrm{~m} / \mathrm{s}$

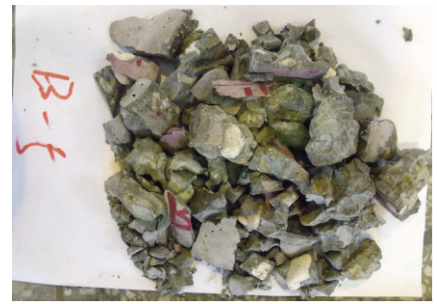

$5.5 \mathrm{~m} / \mathrm{s}$

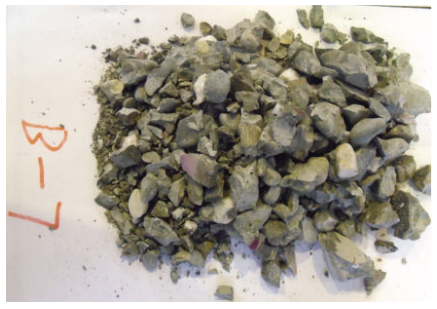

$9.0 \mathrm{~m} / \mathrm{s}$

(a) PC-0

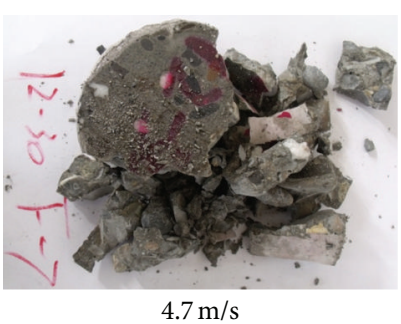

$4.7 \mathrm{~m} / \mathrm{s}$

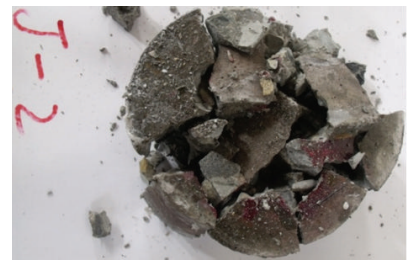

$4.9 \mathrm{~m} / \mathrm{s}$

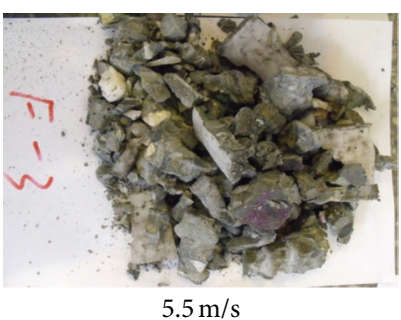

(b) RC-25

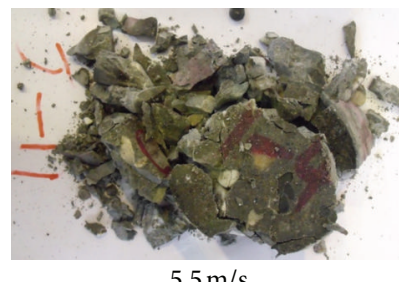

(c) RC-75

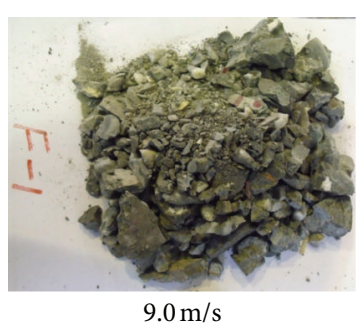

$9.0 \mathrm{~m} / \mathrm{s}$

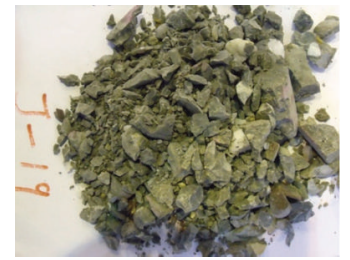

$9.0 \mathrm{~m} / \mathrm{s}$

FIGURE 7: Failure patterns of RAC specimens under various striking velocities.

TABLE 4: Parameters in (4) for RAC specimens.

\begin{tabular}{lccccc}
\hline & PC-0 & RC-25 & RC-50 & RC-75 & RC-100 \\
\hline$a$ & 1.95 & 0.99 & 0.92 & 0.68 & 1.32 \\
$b$ & 0.026 & 0.016 & 0.026 & 0.033 & 0.017 \\
$R^{2}$ & 0.61 & 0.29 & 0.53 & 0.73 & 0.35 \\
\hline
\end{tabular}

TABle 5: Parameters in (5) for RAC specimens.

\begin{tabular}{lccccc}
\hline & PC-0 & RC-25 & RC-50 & RC-75 & RC-100 \\
\hline$c$ & -72.78 & -36.07 & -14.22 & 8.99 & -14.76 \\
$d$ & 15.29 & 12.35 & 7.13 & 5.93 & 6.74 \\
$e$ & -0.048 & -0.15 & -0.015 & -0.0079 & -0.022 \\
$R^{2}$ & 0.99 & 0.96 & 0.95 & 0.98 & 0.84 \\
\hline
\end{tabular}

peak strain-rate. The relationship between the specific energy absorption and peak strain-rate can be expressed as

$$
U=c+d \dot{\varepsilon}_{s}+e \dot{\varepsilon}_{s}^{2}
$$

in which the parameter values of $c, d$, and $e$, and the coefficients of determination $R^{2}$ are summarized in Table 5 .
In addition, it can be seen in Figures 8(c)-8(d) that the specific energy absorption and its increase velocity of NAC specimens are largely greater than those of RAC specimens. Hence, the efficiency of absorbing impact energy of NAC specimens is higher than that of RAC specimens.

\section{Conclusions}

A $100 \mathrm{~mm}$ diameter SHPB system was used to investigate the mechanical properties of RAC specimens at high strain-rates in the range of $10-100 \mathrm{~s}^{-1}$. The main conclusions can be drawn below.

(1) The impact properties of RAC specimens, including dynamic compressive strength, critical compressive strain, and specific energy absorption exhibit obvious strain-rate dependency and increase with the increase of peak strain-rate.

(2) The DIF of RAC specimens is reduced with the increase of RCA replacement ratio. When the peak strain-rates are over the transition strain-rate, the DIF of RAC specimens is largely smaller than that of NAC specimens. 

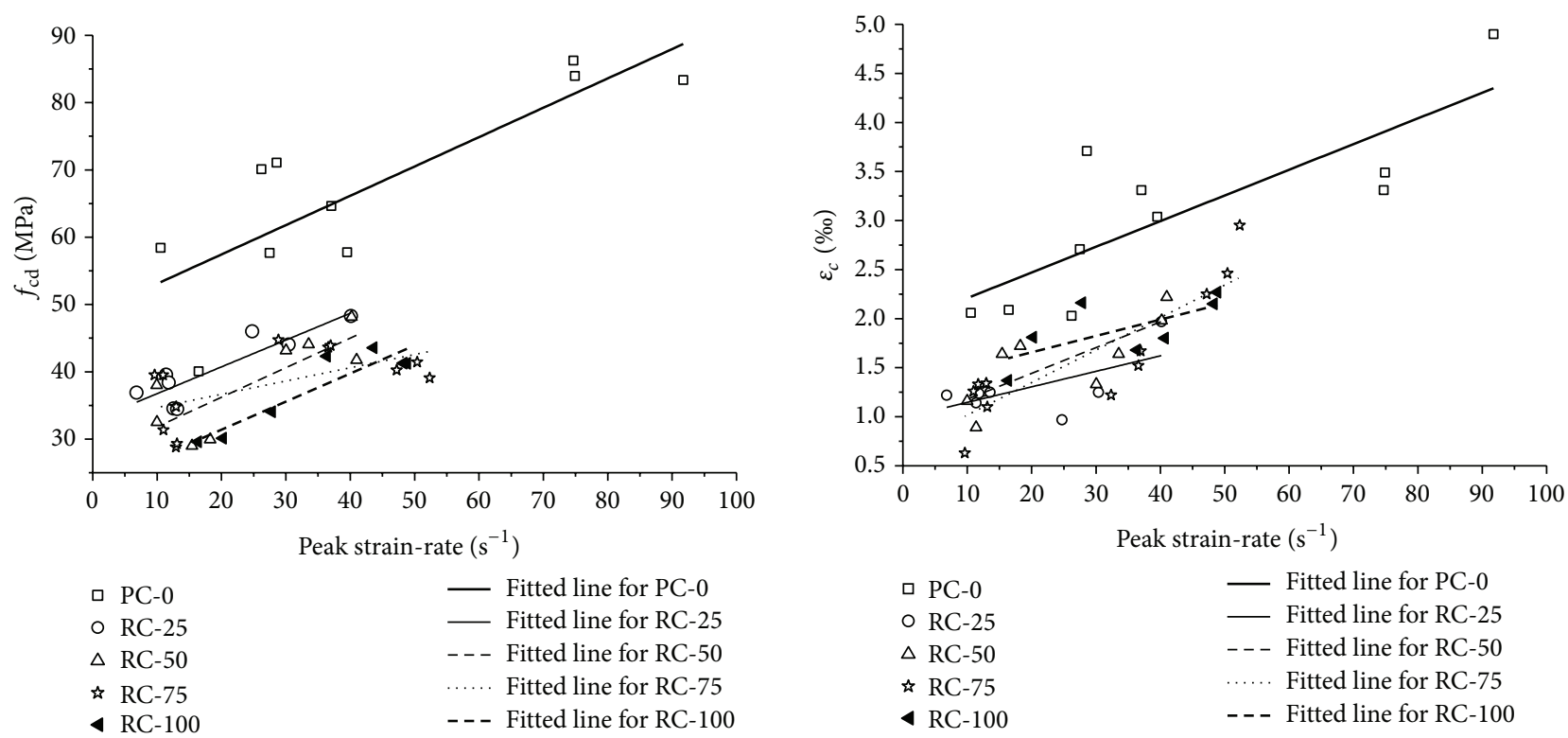

口 $\mathrm{PC}-0$

○ RC-25

$\triangle \mathrm{RC}-50$

\& $\mathrm{RC}-75$

RC-100
- Fitted line for PC-0

- Fitted line for RC-25

- - - Fitted line for RC-50

..... Fitted line for RC-75

- - - Fitted line for RC-100

(b)

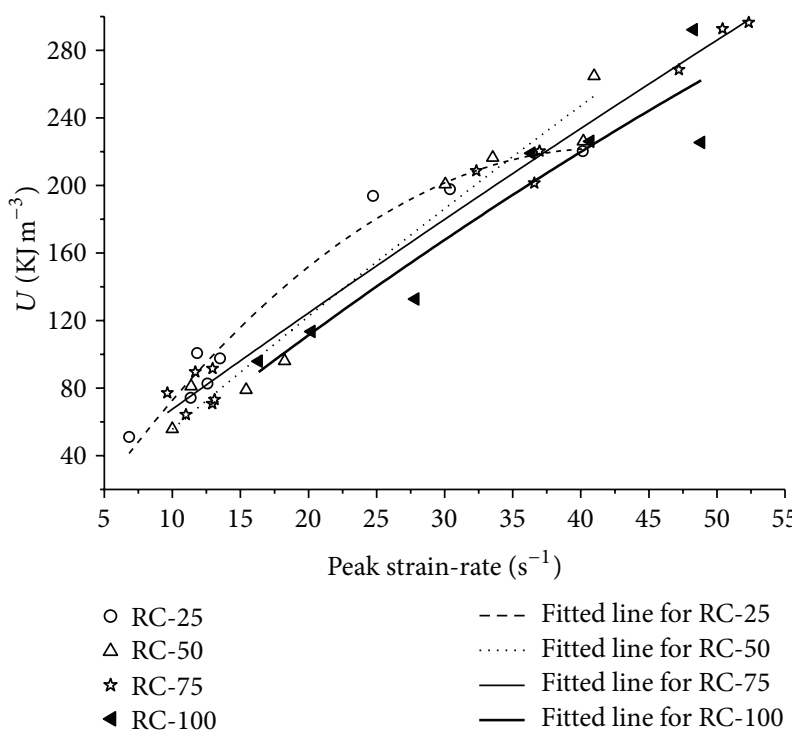

(d)

(c)

FIGURE 8: Dynamic compressive strength and critical compressive strain versus peak strain-rate for RAC specimens.

(3) The critical compressive strain of RAC specimens is smaller than that of NAC specimens. Thus, the deformation capacity of RAC specimens is weaker than that of NAC specimens.

(4) The specific energy absorption and its increased velocity of NAC specimens are largely greater than those of RAC specimens. Hence, the energy absorption capacity of RAC specimens is lower than that of NAC specimens.

Besides, as this study shows that the dynamic compressive properties of RAC are much inferior to those of NAC, and most of the dynamic compressive properties deterioration of
RAC is exhibited between $0 \%$ and $25 \%$ of the replacement ratio, while up to $100 \%$ of the replacement ratio the deterioration is not so severe. To further explain these phenomena and improve the dynamic behavior of RAC, following studies are ongoing by the use of microscopic approaches to investigate the effect of RCA and interfacial transition zone on RAC dynamic properties.

\section{Acknowledgments}

The First author would like to acknowledge the support by the Open Project of State Key Laboratory Cultivation Base for Nonmetal Composites and Functional Materials (10zxfk06) 


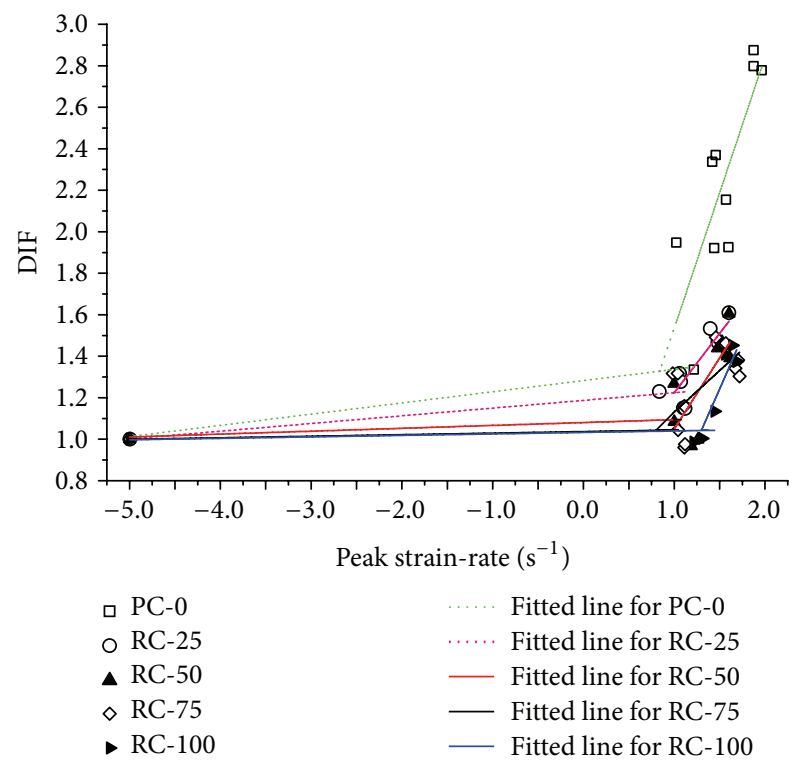

FIGURE 9: Relationships between DIF and peak strain-rate for RAC specimens.

and the Doctorate Foundation of Southwest University of Science and Technology (10zx7141).

\section{References}

[1] W. Li and J. Xu, "Mechanical properties of basalt fiber reinforced geopolymeric concrete under impact loading," Materials Science and Engineering A, vol. 505, no. 1-2, pp. 178-186, 2009.

[2] Z. Rong, W. Sun, and Y. Zhang, "Dynamic compression behavior of ultra-high performance cement based composites," International Journal of Impact Engineering, vol. 37, no. 5, pp. 515520, 2010.

[3] Z. L. Wang, Y. S. Liu, and R. F. Shen, "Stress-strain relationship of steel fiber-reinforced concrete under dynamic compression," Construction and Building Materials, vol. 22, no. 5, pp. 811-819, 2008.

[4] M. Chakradhara Rao, S. K. Bhattacharyya, and S. V. Barai, "Behaviour of recycled aggregate concrete under drop weight impact load," Construction and Building Materials, vol. 25, no. 1, pp. 69-80, 2011.

[5] G. Ravichandran and G. Subhash, "Critical appraisal of limiting strain rates for compression testing of ceramics in a split Hopkinson pressure bar," Journal of the American Ceramic Society, vol. 77, no. 1, pp. 263-267, 1994.

[6] Y. B. Lu and Q. M. Li, "Appraisal of pulse shaping technique in split Hopkinson pressure bar tests for brittle materials," International Journal of Protective Structures, vol. 1, no. 3, pp. 363390, 2010.

[7] P. H. Bischoff and S. H. Perry, "Compressive behaviour of concrete at high strain rates," Materials and Structures, vol. 24, no. 6, pp. 425-450, 1991.

[8] T. X. Yu and G. X. Lu, Energy Absorption of Structures and Materials, Chemical Industry Press, Beijing, China, 2005. 

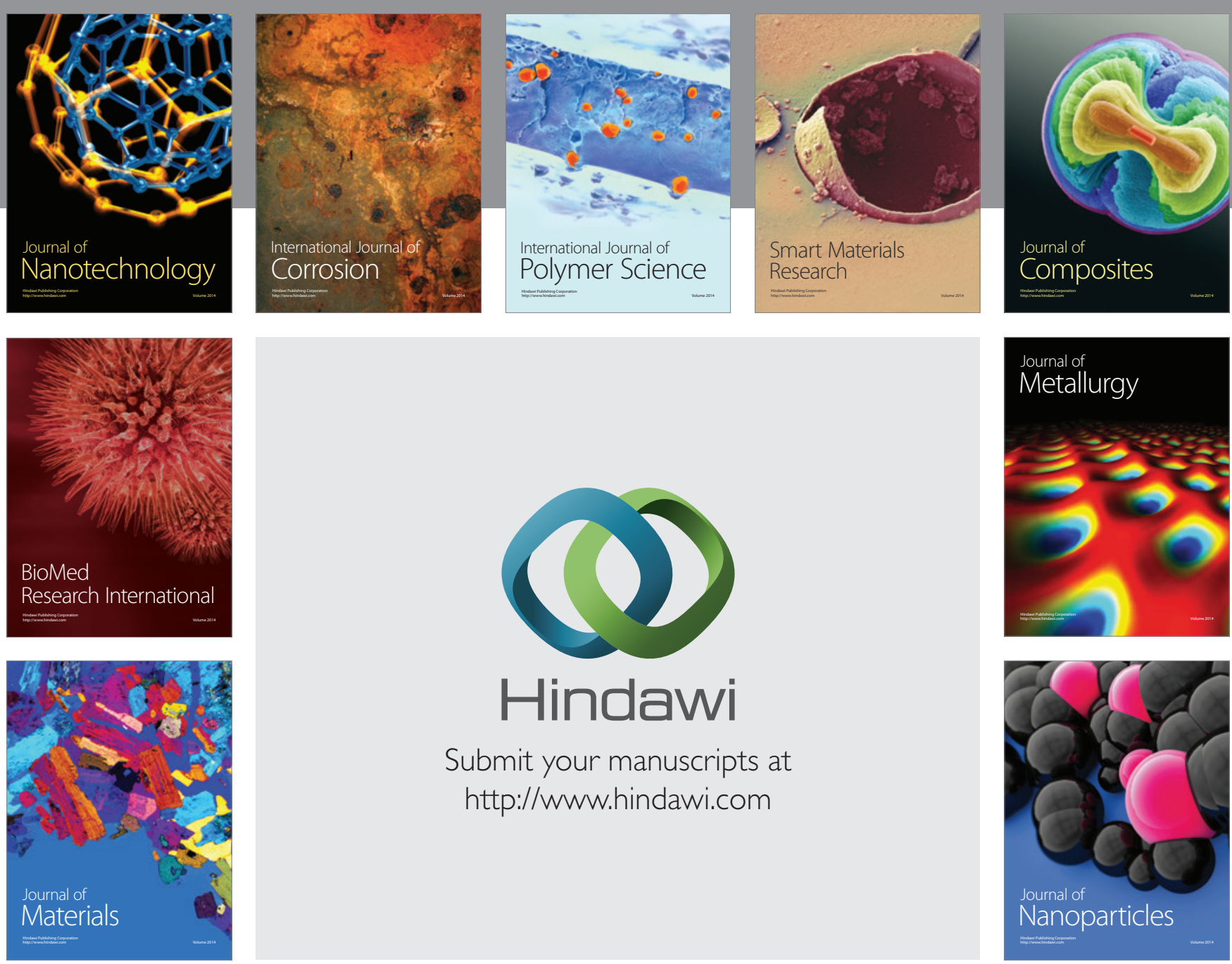

Submit your manuscripts at http://www.hindawi.com
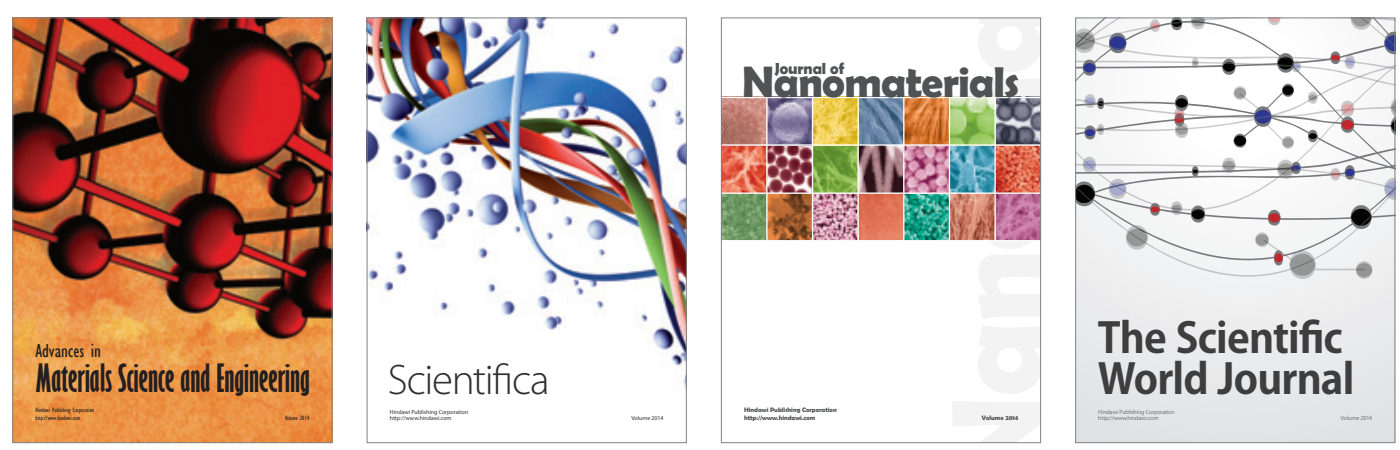

\section{The Scientific World Journal}
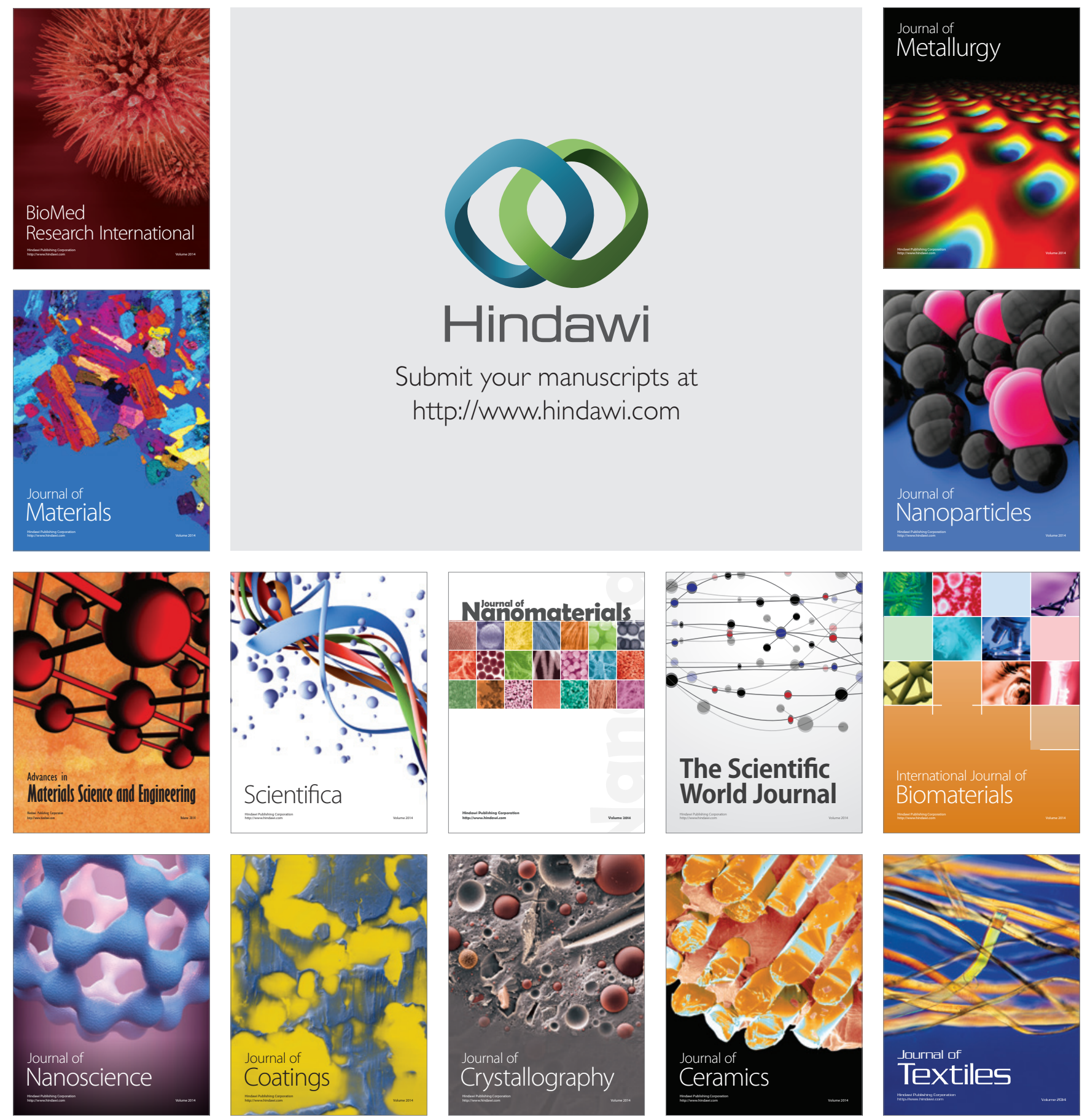